\title{
Queer Therapy, Queering Therapy: Desire in Struggle
}

\section{*}

Paolo Plotegher is based in Glasgow where he works as an art therapist. Prior to their clinical training Paolo was involved for many years in self-organised experimentations inspired by the work of Felix Guattari, Silvia Federici and Starhawk. <paoloplot@gmail.com> ORCID: 0000-0003-2335-1922
Abstract This text draws on personal experience, on the notion of desire in Gilles Deleuze and Felix Guattari, and on possible learnings from the Black Lives Matter movement, to propose an outline of a queering (art)therapy that brings at its core the personal and political struggle of desire.

Keywords Art psychotherapy, Black Lives Matter, Desire in Deleuze and Guattari, Intersectionality, Queer studies. 


\section{Terapia queer, queering terapia: desejo em luta}

Resumo Este texto é baseado numa experiência pessoal, na noção de "desejo", proposta por Deleuze e Guattari, e em possíveis aprendizagens decorrentes do movimento Black Lives Matter, para propor um esboço de uma (arte)terapia queer, que tenha em seu núcleo a luta pessoal e a política de desejo.

Palavras chave Arte Psicoterapeutica, Black Lives Matter, Desejo em Deleuze e Guattari, Interseccionalidade, Estudos Queer.

\section{Terapia queer, queering terapia: deseo en lucha}

Resumen Este texto se basa en la experiencia personal, en la noción de deseo en Gilles Deleuze y Felix Guattari, y en posibles aprendizajes del movimiento Black Lives Matter, para proponer un esbozo de una (arte)terapia queering, que tiene en su núcleo la lucha personal y política de deseo.

Palabras clave Arteterapia, Black Lives Matter, Deseo en Deleuze y Guattari, Interseccionalidad, Estudios Queer. 
At the beginning of my placement with the residents of the Philadelphia Association's houses, as part of an assessment where we talked of class, race, gender, sexual orientation, ability, I introduced myself as queer. Some residents were familiar with the term, and used it for themselves, for some others the term was new. I explained that for me the term "queer" is not defining an identity in the same way that "gay" does, quite the contrary "queer" has the potential to undo identities constructed around gender and sexual orientation. "Queer" is someone who actively questions, in their everyday life, categories like gender and sexual orientation. In this sense it doesn't matter whether queer people are "gay" or LGBTQ+ or not.

I like to think "queer" in this broader sense, as a term to actively struggle with, more than an easy one that you use to define yourself and your identity. It's then important to move from queer as an adjective to queer as a verb: "queering". Everything can be queered, in the etymological sense of "making weird". I learned this when, some years ago now, I joined in London "House of Brag", a queer social centre that for a couple of weeks had a daily programme of activities where everything was queered: from pop songs, to poetry, to communal dinners, the task was to make everything different from how it was perceived out there, outside the squatted pub we occupied. And "House of Brag" was not just happening inside the squatted pub, which was nonetheless open to people from the outside, the bragging was also in the streets, at least for some people, and the right to affirm queer desires was taking over the neighbourhood, sometimes meaning that people would come back with a black eye.

I came to realise only recently that queer is more than another term for weird. To get to that understanding it was useful for me to reflect about my own experience of growing up as a "gay boy" in a super catholic working class family of a very provincial town in the north of Italy. When I stared at guys in the street whilst feeling something happening in my belly, I felt scared and confused. I knew very well that what I was experiencing was not supposed to happen. And yet somehow that sense of fear and astonishment was paired with a feeling of pleasure. Queer has to do with weird, but it also has to do with desire and a struggle around a desire that is not accepted nor acceptable, it's often not accepted by the very people around you, people you love, family and friends, because if you are a boy you must be attracted to girls.

And this desire is not accepted also by random people in the streets, who laugh at you (but I haven't done anything yet...) and shout at you or whisper "frocio" into your ear, even before you know what faggot means. And so, desire learns to move in different ways, and this is a struggle. Many things can happen in the meandering and reshaping of desire. At first it's very hard because it feels you are completely isolated in this struggle of desire. You then might repress desire, or you might learn to hide it, and it then starts swirling like crazy within yourself, bottled up, and then perhaps it begins escaping from all sides, dramatized, in the most unsuspected interstices of life, and what do you do with it? At some point you get to see 
that you are not by yourself with it, and this desire gets at its best when it becomes collective. Desire is much more than having sex, it does all sorts of things, it's a bit like love, it makes the world go round, although not in straightforward trajectories.

Gilles Deleuze and Felix Guattari use "desire" in such a way, moving away from a classic Freudian-Lacanian notion of desire whilst bringing it at the core of their practice (DELEUZE, GUATTARI, 2004). I will try to explain desire according to Deleuze and Guattari in my own words because I think it would be useful in this context. Whilst Deleuze identified as a philosopher and worked as a university teacher, Guattari trained with Lacan as a psychoanalyst and then worked for most of his life at La Borde, a clinic founded and run by Jean Oury, who was also close to Lacan (DOSSE, 2010). Oury had an interest in phenomenology and trained together with Tosquelles, an anarchist who worked as a psychiatrist with the republicans during the civil war in Spain and then escaped to France when the fascist regime took over (TOSQUELLES, 1987). As you can see, this genealogy is complex, but it's important to sketch it here to get a sense of what Deleuze and Guattari do with desire. So, Guattari was coming from a classic Freudian-Lacanian tradition, but a radically politicised version of it (POLACK, 2011). After the encounter with Deleuze he would move towards experiences of systemic therapy, outside of La Borde, through his friendship with the systemic therapist Moni Elkaim. When it comes to desire we could say that Deleuze and Guattari keep it central in their own thinking and practice, somehow in line with the Freudian tradition, but they also profoundly change the psychoanalytic notion of desire. It's important to say that Deleuze and Guattari are still in line with the Freudian tradition because this is very different from the British tradition of the context where I trained and where I work, which replaces, it could be said, the centrality of desire with safety. Starting from Melanie Klein there has been a shift of concern from desires, drives and affects, to the need to establish safety as paramount in clinical practice, within and outside the NHS so that safety becomes central not just for mental health but for the human condition and becomes the overall condition and goal that psychotherapy and any other clinical practice has to aim at.

Going back to desire, we could say that desire in Freud and Lacan is a desire involving lack and a dynamic that moves from subject to object, whilst in Deleuze and Guattari there is no lack coming together with desire, and subjects and objects are not referents any longer, desire moves and puts everything in motion, and it has no beginning nor end. To place this desire at the core of a (therapeutic) practice means to unleash it's potential for transformation in a configuration that moves away from the centrality of human subjects in the cosmos. In this sense it opens psychotherapy to something more than people and their relationships. Guattari's practice gets close to systemic therapy, and yet desire in Deleuze and Guattari operates beyond systems, if systems are considered coherent units, as much as individuals are often considered. This is also why Guattari doesn't end up being a systemic therapist, he moves into ecological activism, bringing 
together "3 ecologies", environmental ecology, socio-political ecology, and an ecology of the psyche (GUATTARI, 2000). Deleuze and Guattari would not define desire as queer or with any other term, but this excursus should be useful to unfold queer desire as something more than the desire I might have to have sex with my next-door neighbour. This desire affects what is human as well as what is not human, it manifests in multiple forms, it intertwines with power dynamics, it flows and put things in motions, it provokes improbable encounters, it's never contained within the self, it is not personal and individual, it mobilises politics, landscapes and contexts. Also, from the perspective of the rational individual, there is something delirious about this desire, desire moves potentially all over.

In the struggle of queer desire there is often something to do with appearing / disappearing, walking the street or hiding in the closet, a struggle between becoming almost invisible and bragging, showing off loudly. There is also often a twisting, which turns the shame of being laughed at in the street into something like a weird desiring kind of humour. Perhaps twisting as "inverting", after the old fashion Italian term "invertito", as gay people used to be called when I was a little child. Queer desire and humour often come together, and there might be pain as well, but there is often joy and a joy that is "gay" in that sense of a collective laughter in the face of oppression. Because queer desire cuts across the normative dynamics of oppression, and the risk, or possibility, is always to make allies in unexpected places and even for the oppressor himself to get invested in this uncontrollable and rather crazy desire.

Just think about some of the stuff that, even traditionally, is part of a queer pop culture: it often has to do with desiring subjects that are not supposed to desire and certainly not in an open and shameless way. But they do, and they form houses and communities and they share friendship, pleasure, conflicts and pain, and there is often a weird sense of humour going around, in the same weird and a bit in-your-face way in which desire goes around. Queer is not just weird, it's also expert in desire and the struggle that comes with it, and this means that queer brings beauty amongst the desolation of mainstream heteropatriarchal culture. And don't forget this beauty that you bring everywhere please! I'll do my best not to forget it myself, and this is not an easy task, to keep pushing it from shame to pride. Thinking differently about families often comes for queer people out of necessity. A family is not just of blood, it is elective and extended, made of relatives but also friends, lovers, animals. When in art therapy I ask people to draw a map of their family is this kind of family that I introduce to them. The map can be made of just names, or people in the shape of animals, or even portraits. You place yourself in the middle of the sheet of paper and what emerges is a constellation you are part of. The "houses" you see, for example, in the TV series Pose, are elective families formed because the relationships with members of your biological family get compromised. When I came out to my super catholic parents I was amazed by their reaction: when I said I didn't tell them before because I thought they would think 
I would burn in hell for eternity, they said that God is love and he loves me as I am. The day after they did suggest I could perhaps talk to a priest about it, but they didn't insist at all when I firmly declined the offer. But to get to that point of smoothness I had first to come out myself from that confusion, torment, fear I had about myself as a "gay guy". It took me several years of not being able to talk at all with my biological family, years when I moved away from my hometown - and to say it all I haven't ever moved back. In those years when I was not talking to my family I desperately tried to find a family in the gay scene in the town of Bologna, by getting drunk in clubs and bars, but for some reason I never really succeeded. I was able to form my own "houses" only much later on, after experimenting with "polyamory" and breaking down, together with others, the classification that usually separates friends, from lovers, from partners, from relatives.

A "queer therapy" should mean not simply therapy with people identifying themselves as queer. From queer therapy we move to queering therapy. In the first year of training as an art therapist, with the residents of the Philadelphia Association, and in different ways in the "wet" homeless hostel in my second year, it felt like we queered psychotherapy together, myself and the residents. Perhaps there was also something there about exposing myself in a certain way, twisting away from the self-invested authority of the therapist to the fragility of a queer desire in struggle. I believe there is something already potentially queer in art therapy and creative therapies in general. I would argue that there is something potentially queer in psychodynamic art therapy, inasmuch as what's at the core of it is not or not only safety, but desire, desire and creativity coming together with what calls for healing.

Queering therapy is to welcome and accompany the process that turns shame into pride in the different circumstances of everyday life, the process that brings you to celebrate and sustain the beauty of queerness wherever you go, the process affirming queer desire and life, from individual to out of the individual closet. But what if you are not queer at all, what if you are solid in your straight, cis identity? We could talk about alliance, but I would also say that it is never too late to question your normality, and queer has been there for all of us since the beginning, it's a matter for it to come back to us, the past comes into the present, and here a question will help: "Can you recall moments in your life when you felt your desire for someone (either human or more than human or other than human) was not accepted or acceptable, when you felt or where made to feel that there was something weird and perhaps even shameful in the way you where sensing, feeling, behaving, thinking in relationship? What happened to you then, what happened to that desire, what did you do to stop the shame, to keep desire under control, to get to be as you thought you were supposed to be?" This could be a question for an art therapy experiential, where through artmaking people would be invited to reconnect with queer moments and possibilities that got lost, buried and forgotten in one's biography. Just so that you experience that the potential is still there. 
Here there is also something about desire for oneself, when you feel weird and inadequate about your sense of being and you are able to recognise and embrace that weirdness. A weirdness and fragility that is potentially there for everyone, to the point that we could turn things around and say that what is really weird is to feel solid and stable in your cis straightness. As a Spanish friend often says, "the difference between straight and queer is six glasses of beer", and the profound sense of this statement is not that if a straight guy gets drunk he'll end up in bed with you, but rather that straightness itself is potentially fragile, as it might take only an alteration of you everyday learned posture to experience that.

I mentioned the past above, and I would say that, amongst the many lessons coming from Black Lives Matter, there is something particularly important about reclaiming a different history and a different past for a different future. I would say that Black Lives Matter brought to the fore an historical and intergenerational understanding of the oppression, the trauma, the struggle of black people, and with the struggle comes something else than trauma and oppression, and in this spirit, it becomes fundamental to reclaim figures from the past that fought that oppression, people that have been too often ignored in schoolbooks. It is especially with regards to trans people that such history of struggle has to be reclaimed because it has been more thoroughly ignored and erased. "We have always been here" this is the first claim in rewriting a history that erased trans people, and even more trans people of colour, and their struggle, and I would like to name Marsha P Johnson and Sylvia Rivera because more of their history has been made recently available. Secondly, to reclaim a history of struggles means to counter the representation of black and trans people as historically oppressed and nothing else than oppressed and traumatised, as a way of saying, no, we have always struggled and fought back, it's Western-centred history that erased that struggle not only by suppressing it but also from the records. Thirdly, to think historically is what makes us more easily understand that we are all implicated in this mess, that there are differences in privileges that are historical, that there is trauma which is historical and intergenerational, that no matter how many black friends you have racism is systemic, institutional, embodied, and historically so, and we are all part of that history. Five: to reclaim a history of struggles means also to educate yourself, to learn through books, films, music, art, and all those expressions that again have been marginalised by mainstream culture. Finally, to reclaim that history, learn it and situate yourself as part of it, involves a painful and continuous recognition of your privileges, but also the possibility of grounding yourself, together with other people, in a history constellated by ancestors, in a lineage that is elective rather than determined by blood.

If I think about the work with the residents of the Philadelphia Association I would say that, taking on board, more or less consciously, the history of that organisation, which was set up in the "60s of the anti-psychiatric movement, we started already a bit beyond the various diagnosis 
assigned to them, by talking about the lived experiences, in their everyday life, of what in psychiatric manuals is called "schizophrenia", "depression", "manic disorders". We started by unpacking diagnosis and giving value, through the artmaking and the art made, of what is not-conforming, of what is not fitting within the diagnosis itself, what escapes from it, slippery. Art was made that would bring up questions about queerness. We gave value and we gave voice to the suffering that not-fitting-in brings, dealing with the tensions provoked by the desire / struggle to actually fit, to have a "normal" life, a "normal" job, "normal" friends. And at the core of all of this there was the weird desire that comes with a therapeutic relationship, within therapeutic boundaries.

Art therapy itself has a history of not fitting-in as a practice. It became popular in the "70s within therapeutic communities and the anti-psychiatry movement in the UK (DUDLEY, 2004). Back then art therapy was also widely practiced within the NHS. Now there is little space for art therapy in it. Much could be said about this shift, that sees art therapists working undercover within the NHS, using different titles, and often, at least in the NHS, whilst being paid less than what an art therapist is supposed to be paid. It was the beautiful weirdness of the artmaking of the Philadelphia Association's residents that allowed us to experience the empowering potential of what does not fit and the desire that comes with it.

Before starting the training, and after House of Brag, I had another experience that helped me give meaning to the term queer and to queering. For a couple of summers, I joined Las Raras, a collective based in Madrid and formed by people who, in different ways, felt "raras", that is, weird: from people with disabilities to trans people, to others with various mental health conditions. Within Las Raras the declinations of "weirdness" were so different that it was impossible for the term to become an all-encompassing label. Las Raras often used this motto: "rarizar la ciudad", to make the city weird, to queer the city. Part of this endeavour was practiced by organising encounters with other groups in Madrid, as potential allies: from associations of LGBT deaf and mute people, to groups of migrant nurses and carers. Las Raras always started these encounters by asking the question: how do you feel weird? They would then carry on proposing "weird" activities, like making together shapes with wet clay and getting messy with it. To queer the city: we don't use the term queer as an identity to distinguish ourselves from the non-queer. Instead, we go out and change together what is designed to erase our weirdness, to block it as the movement of disabled people is blocked by the barriers of urban design, as the flow of queer desire is blocked by the stratification of patriarchal white supremacy.

Perhaps, thinking of that Raras experience again now, the force that enabled us that radical change of perspective, from identitarian defensiveness to claiming back the city, was some kind of collective intersectionality in action, or rather, with a more appropriate term, transversality: the coming together of otherness within otherness, we were all queer but we were all so amazingly different from each other, and for the first time I got 
a bit more of a sense of the everyday struggle of someone on a wheelchair, and this was because of the generosity and care people had in sharing and explaining things to each other.

Transversality it's a more appropriate term to define Las Raras also because that experiment came out of a series of workshops organised by Paul B. Preciado where the notion of transversality animated the discussions. Transversality comes from the experience of Guattari at La Borde clinic, and it can be seen as going against the grain of the verticality of hierarchies and the horizontality of something like peer-to-peer work (e.g. we are all "queer" and that is what defines ourselves and this is our shared identity and you are either in or out). If we think about La Borde, the clinic had actually a hierarchical structure with Jean Oury as a director, but it had also different substructures, arrangements and tools to generate transversality. One of these tools was the "grid", a system that would allow different people at La Borde to engage with each other despite and beyond their different roles and identities, so that, for example, a gardener would sometimes assist a nurse and have a different kind of encounters with patients, and the other way round (DOSSE, 2010). Tools like this were not used to make the management of the clinic more efficient, in fact the use of the grid would often upset the workers and generate conflicts and heated discussions. The point was not to make things smoother but to have desire flow so that unusual and out-of-role encounters, even if sometimes challenging, would counter identitarian fixity and alienation and put life in motion. Transversality has to do with identity, we might have a role / identity, as nurses, gardeners, patients (or as queer, white, of a working class background...) and we are also something else and much more at the same time. And we are always in relationship and in a context, territory, landscape, structured by affiliations, groups, institutions. Transversality is generated through tools that question the fixity of identities and roles and make encounters across difference possible. In other terms, identitarianism kills desire, and transversality counters this tendency.

Intersectionality is something else than transversality, it is a framework to understand the complexity of our identities, and both the oppression and privilege that come with this complexity. To bring intersectionality together with transversality turns it potentially into something that not only makes us understand the complexity of our identities, oppression and privilege, but also helps us moving away from identity fixations, it makes us sense those categories as artificial, although powerful because socially recognised (am I an art therapist or is that my role as a worker?), and it helps us thinking not so much in terms of individuals in empty spaces, as neoliberalism does, but about our shared terrains, landscapes, contexts and how we can possibly shape them so that encounters and engagements across difference (and beyond people) can intensify and multiply. There is something to do with intersectionality in this text, in the sense that it attempts to unfold queer and queering across identity categories, suggesting the 
possibility of encounters through potential commonalities and difference: the queering of children, as well as madness, LGBTQ+, people of colour, and ultimately, anyone. Desire puts intersectionality in motion.

Queering therapy might also mean to queer gender. Genderqueer is the term I use to identify my gender and it took me some time to get to this point, partly because I was afraid of claiming for myself an identity that for others would come with painful struggle. Then I realised that my struggle around gender has been painful enough. Most of all, at some point I realised that my idea of gender and transgender was completely distorted as it was coming from mainstream patriarchal culture. It sounded like this: "I am not trans because I am fine with my willie and I don't want to cut it off, and I don't feel like I am a woman trapped in the body of a man." The first problem with this kind of thinking is not being able to distinguish sex as biological from gender as culturally constructed. The second problem is not being able to see anything else than men and women and no alternatives to this binary opposition. Biological sex itself should be understood as a spectrum and not as a genital matter of fact, as I learned in a workshop on intersex at House of Brag. And gender itself is a cultural construction, it's when I understood this difference and when I started talking with friends about it that I realised that I never identified as "male" in the way I was expected to, that I always felt something else. I never felt like a girl either, I felt different, not fitting as a boy within the boys, and this had not to do with sexual orientation, it had to do with gender in the first place. And this is why, as a child, I would spend most of the time by myself, certainly not with the boys, and I would rather identify with a witch that was the most powerful monster fighting the good guys in Jeeg Robot, my favourite cartoon on TV.

After graduating as an art therapist, I started working with children, and I realised that there is something queer about children as well. It's often said that children have no filters. Desire for children is also a desire in struggle, and adults are often trying to put it in place, by suppressing it, ignoring it, minimising it. This is where art therapy comes in, offering a space where weird desire can be expressed, and here it is weird because it's not an adult heteropatriarchal desire. "Oh, it's just children you know..." Children are cra$z y$, and queers are crazy too, and they are sometimes described as childish as well. The difference with children is that desire for them is not so fixated with human beings, it tends to flow everywhere, investing everything, plants, animals, stars, and all sorts of more-than-human beings, in ways that are sometimes difficult for adults to make sense of. Children have a powerful ability to imagine and create worlds that, in my experience as an art therapist, if brought at the core of the therapeutic process relationally, can have powerful healing effects. And yet I'd say that most of the time this queering ability children have, this ability of bringing even joy and excitement when coming to terms with pain, goes largely unseen, to give space to fight / flight, freeze and flop, safety and emotional regulation. Reducing children to their dependency on adults is also a way of disempowering them, avoiding to acknowledge their power-struggle with the adults they are dependent of. 
When I worked as an art therapist in an acute ward I thought again about the meaning of queer in relation to therapy. Madness in a way is so much about queer desire, perhaps this time a desire that moves away even more from people, to invest everything else, history, the cosmos... there is something both cosmic and very bodily and material about this desire, and the challenge of art therapy, again in my experience, is to ground it, to anchor it, to reconnect it with the here and now, with the relationship with others in the room, without suffocating it. The sheet of paper in art therapy helps already, and so does the folder, as well as the material setting of the room. I believe it's also important, for this desire that moves all over, and at the same time can end up being so much tied to one individual, to be witnessed, to be mirrored, to be hold and contained, to be reshaped together, through the artmaking and the therapist as well, whenever possible. The struggle for mad people and their desire is historically related to institutions, and specifically mental health institutions, and from there to society at large: mad "pride" is called, and for me getting to know about Mad Pride, and getting to know the Mental Health Resistance Network people and to get a sense of how they practice solidarity and "radical mutual care", helped me understood a bit better the meaning of pride in gay pride, from shame to pride, from hiding in a closet or a mental health institution, to collectively claiming the right not to conform (DELLAR, 2003).

When, as an art therapist, I read about narcissism, I thought again about queer and about the stereotype of the gay narcissist. Freud says that the child doesn't grow out of narcissism if there is no one else around to love, and so he ends up loving himself (FREUD, 2014). Reading this made me think this might apply not only to little children in relation to their mum, but also to a bit older people with anyone around them. Narcissistic injuries result from being ignored, unseen, you and your love and desire, and these injuries come together with shame, again, when you grow up. You end up obsessing with yourself because it seems like there is no one else around to love, because to love someone else is far too dangerous. Psychoanalysis refers to a mother who is not emotionally available for her baby, but thinking about my own experience, narcissism is something that comes back, when you are a teenager and there is no one around you can love or are entitled to love, because it's too terrifying and you are full of shame. On a broader level, narcissism it's very much engrained in neoliberal culture, with its obsession with the individual separated from a society that is declared as not existent any longer. We can understand narcissism as a neoliberal effect of desire confined into the individual, a form of repression, of de-politicisation, you end up obsessionally loving yourself because you are too scared of loving anyone else, even if it's someone of the opposite sex. Narcissism can turn into something else when the separation between yourself and others enters a crisis. The way out of narcissism could be on the same lines of its histrionism and theatricality, if crossing the safety of the identitarian individualised stage. Coming out can be seen as countering narcissism, a coming out of desire. 
In the "wet" homeless hostel I did not discuss the term queer when introducing myself, although residents voiced from the beginning the possibility for me not the be straight, already in the "art therapy taster" session. People who in many years never ever took part in an organised activity came to the art therapy open group. People I was told it didn't make sense to try with joined the session and came back. I believed this happened also because the sessions got "queered", through negotiations between the residents and myself. Coming to sessions was not easy for many of the residents and yet they sometimes made it, nonetheless. Sometimes the "sessions" would happen in the corridor and sometimes people never made it to the group. Some other residents came only to the very last session, engaging in ways that they might not have felt doing otherwise if it was not the last one.

Something that took place in those sessions was perhaps the sense of a shared weirdness, as not really fitting with what's expected from you by mainstream culture and society. I believe the sessions also offered a space where residents could be "normal", that is, they could be just there, without being judged, perhaps playing a normal person, sometimes a rebel, but always within a space where what you have to say or not to say, the art you make or don't make, finds ways of getting expressed, it gets shown, it appears, it gets shared, sometimes even with humour and joy, like a weird desire investing people and things.

I would like to end this text with a summary that could work as an indication of a mini program for queering therapy, in the hope not to close down too much what I tried to open up here. The following should not be read as a set of goals of queering therapy, but rather as possible effects.

- Queering therapy can help people embracing desire in struggle.

- Queering therapy can help people engaging with difference and what is different, either human or more-than-human.

- Queering therapy can help people reconnecting personal struggles with social struggles.

- Queering therapy can help people experiencing desire in struggle and the struggle of desire not in terms of goals to achieve but as a process.

- Queering therapy can empower people, not in the sense of power over, but as an ability to embrace your own fragility, in relationship, and perhaps even by showing it off in all its delicate beauty.

- Queering therapy can help people shifting from shame to pride, with the awareness that this shift is never conclusive and always contextual. 
- Queering therapy can help people appreciating and celebrating the beauty of what does not conform to the norm, in and outside yourself.

- Queering therapy can help people rethink their relationship with gender.

- Queering therapy can help people countering the individualisation of neoliberal culture, which reduces difference to the fantasy of an individual freedom against the rest of the world.

- Queering therapy can help people forming elective families.

- Queering therapy can help people connecting with their ancestors.

- Queering therapy can help people countering the microfascism of exclusionary and defensive identitarian formations.

- Queering therapy can help people countering patriarchy and queer-phobia.

- Queering therapy can help people keep coming out, whatever this might mean for you and people around you, and it helps bringing humour, laughter and joy into the process.

- Queering therapy can help people sensing, feeling, thinking, experiencing desire not as individual desire for commercialised identitarian categories, but as political, as multiple and collective, in the struggle for it to come out. 


\section{References}

BARKER, M-J. Rewriting the Rules, Routledge, 2018.

CALO', S. 'The Grid', Axiomatic Earth, Tecnosphere Issue, Anthropocene Curriculum \& Campus, House of World Cultures (HKW), On-line at: http://www.anthropocene-curriculum. org/pages/root/campus-2016/axiomatic-earth/the-grid/

CRENSHAW, K. Demarginalizing the Intersection of Race and Sex: A Black Feminist Critique of Antidiscrimination Doctrine, Feminist Theory and Antiracist Politics". University of Chicago Legal Forum. 1989 (1).

DEGRUY, J. Post-Traumatic Slave Syndrome, Uptone Press, 2005.

DELEUZE, G.; GUATTARI, The Anti-Oedipus, Minneapolis: University of Minnesota Press, 2004 [orig. 1972]

DELEUZE, G.; GUATTARI, F. A Thousand Plateaus, London: Athlone, 1989.

DELLAR R. Ed, Mad Pride: A Celebration of Mad Culture, Chipmunka: London, 2003.

DOSSE, F. Deleuze and Guattari Intersecting Lives, Columbia, 2010.

DUDLEY J., "Art Psychotherapy and the Use of Psychiatric Diagnosis: Assessment for Art Psychotherapy”, International Journal of Art Therapy, 9:1, 14-25, 2004.

FREUD, S., "On Narcissism: An Introduction”, in Sandler, J. et al. Eds. Freud's 'On Narcissism': An Introduction, London: International Psychoanalytical Association, pp. 3- 32, 2014. GUATTARI, F. The Three Ecologies, London: Athlone, 2000.

GUATTARI, F. and ROLNIK, S., Molecular Revolution in Brazil, Los Angeles: Semiotex$\mathrm{t}(\mathrm{e}), 2008$.

MISSE', M. A la conquista del cuerpo equivocado, Egales, 2018.

POLACK, J-C. "Analysis between Psycho and Schizo", in ALLIEZ, E. and GOFFEY A. Eds., The Guattari Effect, Continuum: London and New York, 2011, pp 57-67.

QUERRIEN, A. "Maps and Refrains of a Rainbow Panther", in ALLIEZ, E. and GOFFEY A. Eds., The Guattari Effect, Continuum: London and New York, 2011, pp 84-98.

LAS RARAS Offbeat diary: Humour and irony allow us to distance ourselves from pain that can sometimes hold us prisoner, in ZECHNER, M. Ed., Una Ciudad Muchos Mundos: Artistic Research and Situated Practices, Matadero: Madrid, 2016, pp 92-105.

INTERMEDIAE MATADERO MADRID. Una ciudad muchos mundos: Investigación artística y práticas situadas. Madrid, 2018 Online at: https://www.unaciudadmuchosmundos.es/sites/default/files/2018-11/UCMM\%20Investigacio\%CC\%81n\%20arti\%CC\%81stica\%20y\%20 pra\%CC\%81cticas\%20situadas.pdf TOSQUELLES, F. "La scuola di liberta", François Tosquelles, interview à cura di GIOVANNA GALLIO e MAURIZIO COSTANTINO. 1987. Available at http://www.persalutementale.altervista.org/files/ScuolaLiberta.pdf.

Recebido: 15 de fevereiro de 2021 . Aprovado: 05 de março de 2021. 